\title{
Correction to: How does light availability affect the aboveground biomass allocation and leaf morphology of saplings in temperate mixed deciduous forests?
}

\author{
Ardalan Daryaei ${ }^{1} \cdot$ Hormoz Sohrabi $^{1}$ D $\cdot$ Carolina Puerta-Piñero ${ }^{2}$
}

Published online: 18 September 2018

(c) Springer Nature B.V. 2018

\section{Correction to: New Forests} https://doi.org/10.1007/s11056-018-9666-0

The original version of this article was inadvertently published without the acknowledgements section.

Acknowledgements We express our sincere appreciation to Younes Shahrokhzadeh, Masoud Ghorbani, and Masoud Khaledi for their valuable assistance in the field work. We would like to thank Dr. Mehdi Abedi and Dr. Fariba Babaei Sustani for their valuable comments on the manuscript. Also, we would like to thank two anonymous reviewers and Associate Editor for their valuable review of the manuscript.

The original article can be found online at https://doi.org/10.1007/s11056-018-9666-0.

Hormoz Sohrabi

hsohrabi@modares.ac.ir

Ardalan Daryaei

ardalan.daryaei@gmail.com

Carolina Puerta-Piñero

carolina.puerta@juntadeandalucia.es

1 Department of Forestry, Faculty on Natural Resources and Marine Sciences, Tarbiat Modares University, Jalal Ale Ahmad Highway, P.O. Box: 14115-111, Tehran, Iran

2 Institute of Agricultural Research and Training (IFAPA), Camino de Purchil sn, 18004 Granada, Spain 